\title{
Testosterone-stimulated growth of the rat prostate may be driven by tissue hypoxia and hypoxia-inducible factor- $1 \alpha$
}

\author{
Stina Häggström Rudolfsson ${ }^{1}$ and Anders Bergh ${ }^{2}$ \\ Departments of ${ }^{1}$ Surgical and Perioperative Sciences, Urology and Andrology and ${ }^{2}$ Medical Biosciences, Pathology, Umeå University, Umeå S-90185, Sweden \\ (Correspondence should be addressed to S H Rudolfsson; Email: stina.rudolfsson@urologi.umu.se)
}

\begin{abstract}
Testosterone-stimulated growth of the ventral prostate (VP) in castrated rats is preceded by angiogenesis, but the mechanisms coordinating vascular and tissue growth are unknown. Adult rats were castrated and some treated with testosterone. Tissue hypoxia was studied morphologically using the hypoxia marker pimonidazole (Hypoxyprobe), hypoxia-inducible factor-1 (HIF-1) $\alpha$, vascular endothelial growth factor (VEGF), and carbonicanhydrase 9 (CA-9) levels by western blotting and quantitative RT-PCR. In the intact untreated prostate, most glands were unstained by the hypoxia marker but already 1 day after castration most epithelial cells in the VP were stained. Seven days after castration prostate glands were apparently normoxic again, and HIF-1 $\alpha$, VEGF, and CA-9 were decreased. Treatment of 7-day castrated rats with testosterone resulted in increased epithelial hypoxyprobe staining and increased HIF-1 $\alpha$, VEGF,
\end{abstract}

and CA-9 levels. The transient increase in tissue hypoxia after testosterone treatment is probably caused by a temporary mismatch between oxygen consumption and supply. Treatment of prostate epithelial cells in vitro under normoxic conditions also increased HIF-1 $\alpha$, and this could be blocked if epidermal growth factor receptor (EGFR) signaling was blocked with gefitinib. In vivo gefitinib could, however, not block the testosterone induced increase in HIF-1 $\alpha$. Testosterone may thus induce HIF$1 \alpha$ and its downstream angiogenesis promoting genes by at least two mechanisms, hypoxia and EGFR signaling. Transient epithelial cell hypoxia could by rapidly increasing HIF-1 $\alpha$ and VEGF be an essential coordinator of testosterone-stimulated vascular and glandular growth.

Journal of Endocrinology (2008) 196, 11-19

\section{Introduction}

Androgens are the principal regulators of prostate growth and homeostasis. Androgen receptors are present on prostate epithelial and stroma cells, and androgens influence prostate growth by effects both in the epithelium and in the stroma (Isaacs et al. 1994, Kurita et al. 2001). We and others have shown that prostate blood vessels and prostate blood flow also play an important role in ventral prostate (VP) growth and regression (Lissbrant et al. 2001). Castration results in apoptotic death of most prostate epithelial cells and tissue involution, but this is preceded by a major decrease in blood flow (Lekås et al. 1997), endothelial cell death and vascular regression (Shabisgh et al. 1999, Johansson et al. 2005), and tissue hypoxia (Shabsigh et al. 2001). Insufficient blood flow and tissue hypoxia could actually trigger the subsequent death of epithelial cells (Lekås et al. 1997, 1999, Buttyan et al. 2000). Similarly, testosterone-stimulated growth of the VP in castrated animals is preceded by a major increase in blood flow, endothelial cell proliferation, and vascular growth (Lekås et al. 1997, Franck Lissbrant et al. 1998) suggesting that prostate growth is angiogenesis dependent (Folkman 1998, Franck Lissbrant et al. 1998).

As androgens regulate prostate growth and homeostasis partly by effects on the vasculature it is of interest to elucidate mechanisms. Do androgens have direct effects on prostate blood vessels (Johansson et al. 2005) or are the effects mediated indirectly by effects on other prostate cells? And if so how? These questions are largely unanswered, but the observations that testosterone stimulates secretion of the potent angiogenic and vasodilatory factor, vascular endothelial growth factor (VEGF) from glandular epithelial cells in castrated animals (Joseph et al. 1997, Häggström et al. 1999), and that neutralization of VEGF bioactivity with a soluble VEGF receptor chimerical protein, $\mathrm{mflt}(1-3) \operatorname{IgG}$ inhibits testosterone-stimulated prostate growth (Lissbrant et al. 2004) suggest that androgen receptor (AR)-positive epithelial cells may use VEGF as a signal to regulate the prostate vasculature. Tissue hypoxia generally increases the levels of hypoxia-inducible factor $1 \alpha(\mathrm{HIF}-1 \alpha)$ and this is the major stimulator of VEGF, and other angiogenesis stimulators, secretion in various tissues (Dor et al. 2001, Giordano \& Johnson 2001, Semensa 2003). It is therefore somewhat surprising that testosterone which increases blood flow in the VP (Lekås et al. 1997) also increases VEGF (Joseph et al. 1997, Häggström et al. 1999). In order to elucidate this apparent paradox further we studied tissue hypoxia, HIF-1 $\alpha$, and VEGF in the rat prostate at different times after castration and testosterone treatment and found that testosterone treatment induces prostate tissue hypoxia and increases 
HIF- $1 \alpha$ and that this may stimulate angiogenesis and coordinate this with prostate tissue growth.

\section{Materials and Methods}

\section{Animals, treatments, and tissue hypoxia}

The experimental design of this study proceeded according to the guidelines for care and management of laboratory animals and was approved by the local animal ethical committee. Animals were housed under a controlled temperature in an artificially illuminated room (12 h light/12 h darkness). Food and tap water were freely available. Adult male Sprague-Dawley rats (300-350 g, B\&K, Stockholm, Sweden) were divided into several groups. Some rats were used as controls and others were castrated via the scrotum. Castrated rats were treated with testosterone esters (Sustanon, Organon, Oss, The Netherlands) given as a single subcutaneous injection of $10 \mathrm{mg} / \mathrm{kg}$ every morning as earlier described (Franck Lissbrant et al. 1998). Intact rats were also injected with 50 i.u. human chorionic gonadotropin (hCG; Organon, Oss, The Netherlands) to stimulate endogenous testosterone secretion and studied 4 and $24 \mathrm{~h}$ later. At different times after castration (1 day, 7 days) or after hCG treatment, the rats were injected intra-peritoneal with the morphological hypoxia marker pimonidazole hydrochloride, $60 \mathrm{mg} / \mathrm{kg}$ (Hypoxyprobe TM-1, Chemicon, Temecula, CA, USA, Raleigh et al. 2001). Similarly, 7-day castrated rats were treated with a single daily dose of testosterone and studied at different times thereafter ( 8 h, 1 day, 2, 3, and 4 days). Castrated and testosterone-treated rats were also treated with the tyrosine kinase inhibitor of EGF-R, gefitinib (150 mg/kg; donated by AstraZeneca, Södertälje, Sweden) as earlier described (Hammarsten et al. 2007). Pimonidazole is a low-molecular weight substance that after systemic injection from protein adducts in all cells in the body with a $\mathrm{pO}_{2}$ of $10 \mathrm{mmHg}$ or lower. Such adducts are then detectable with a specific monoclonal antibody (Hypoxyprobe TM-1Mab1, Natural Pharmacia International Inc., Belmont, MA, USA) following the manufacturer's instructions. One hour after intra-peritoneal injection of pimonidazole the rats were anesthetized and then fixed by vascular perfusion with buffered formalin, the prostate glands, seminal vesicles, the liver and the kidneys were removed, postfixed, dehydrated, and embedded in paraffin as earlier described (Franck Lissbrant et al. 1998). Four-micron thick sections were immunostained to detect tissue hypoxia following the manufacturer's instructions. Sections from the kidney and the liver were used as controls as these tissues normally contain parts with a $\mathrm{pO}_{2}$ lower than $10 \mathrm{mmHg}$ (Raleigh et al. 2001).

Other rats were treated as described but instead of perfusion fixation the tissues were removed and frozen in liquid nitrogen.

\section{Cell line, culture conditions, and reagents}

The human prostate epithelial cell line RWPE-1 was purchased from American Type Culture Collection (by way of LGC
Promochem, Borås, Sweden) and was maintained in Keratinocyte Serum-Free medium supplemented with $5 \mathrm{ng} / \mathrm{ml}$ human recombinant EGF and $0.05 \mathrm{mg} / \mathrm{ml}$ bovine pituitary extract (KSF medium, Invitrogen, formerly GIBCO-BRL) at $37^{\circ} \mathrm{C}$ in a humidified atmosphere and $5 \% \mathrm{CO}_{2}$ in air.

R1881 and flutamide were obtained from Sigma-Aldrich. Cells were seeded in six-well culture dishes and grown in KSF medium until $50 \%$ confluence. The medium were then replaced with KSF medium without supplement. After $24 \mathrm{~h}$, the medium was refreshed and $1 \mathrm{nM}$ R1881 (dissolved in 100\% ethanol), 1 or $10 \mu \mathrm{M}$ flutamide (dissolved in dimethyl sulfoxide (DMSO)), $100 \mathrm{ng} / \mathrm{ml} \mathrm{EGF,} 1$ or $10 \mu \mathrm{M}$ gefitinib (dissolved in DMSO), or vehicle $(0 \cdot 1 \%$ ethanol or $0 \cdot 1 \%$ DMSO) were added and the cells were incubated for 2 days. Cells were washed with PBS and resuspended in cold lyses buffer A (see below).

To explore mechanisms behind pimonidazole staining RWPE-1 cells were grown in an incubator (BillupsRothenberg, San Diego, CA, USA) at 21 or $1 \% \mathrm{O}_{2}$, at $37^{\circ} \mathrm{C}$ for $2 \mathrm{~h}$ in $\mathrm{KSF}$ medium containing $100 \mu \mathrm{M}$ pimonidazole hydrochloride (Chou et al. 1996). Cells were washed with PBS to remove unbound pimonidazole, harvested by cytospin, fixed with acetone, and immunostained with an antibody for pimonidazole adducts as described above.

\section{Protein extraction and Western blot}

Frozen prostate tissues were pulverized in a micro-dismembrator (Braun, Biotech International, Sweden) and suspended in cold lyses buffer A (10 mM HEPES pH 7.9, $10 \mathrm{mM} \mathrm{KCl,}$ 0.1 mM EDTA, 0.1 mM EGTA, $1 \mathrm{mM}$ dithiothreitol (DTT), supplemented with complete protease inhibitors Boeringer Mannheim AB). Samples were incubated on ice for $20 \mathrm{~min}$, $0 \cdot 6 \%$ NP-40 was added, and cytoplasmic fraction (supernatants) were collected following refrigerated centrifugation. The resulting pellet was vigorously shaken, $4{ }^{\circ} \mathrm{C}$, in buffer $\mathrm{C}$ (20 mM HEPES pH 7.9, 0.4 M NaCl, 1 mM EDTA, 1 mM EGTA, $1 \mathrm{mM}$ DTT, and complete protease inhibitors) and nuclear extract was recovered following refrigerated centrifugation. Alternatively, whole-cell protein lysates were extracted in lyses buffer (7 M urea, $2 \mathrm{M}$ thiourea, 2\% CHAPS (3-[(3cholamidopropyl)-dimethylammonio]-1-1 propane sulfonate), $30 \mathrm{mM}$ Tris $\mathrm{pH} 8 \cdot 5$, supplemented with complete protease inhibitors). Protein concentrations were determined with BCA Protein Assay kit (Pierce, Rockford, IL, USA) or 2D Quant kit (Amersham Bioscience). For Western blotting, protein samples were electrophoresed on $7 \cdot 5 \%$ and $12 \%$ SDS-polyacrylamide gels under reducing conditions and fractionated proteins were electrophoretically transferred onto PVDF membranes (Amersham Bioscience). Membranes were blocked in 5\% dry milk, $0 \cdot 05 \%$ Tween-20 in PBS prior to incubation with mouse monoclonal antibody against human HIF-1 $\alpha$ (BD Transduction Laboratories, Stockholm, Sweden), rabbit polyclonal antibody against VEGF-A (Santa Cruz Biotechnology Inc., Santa Cruz, CA, USA), rabbit polyclonal antibody against carbonic anhydrase 9 (CA-9, Novus Biologicals, Littleton, CO, USA), and rabbit polyclonal antibody against actin (Sigma-Aldrich). 
After incubation with peroxidase-conjugated secondary antibodies (Amersham Bioscience) proteins were detected using enhanced chemiluminescence detection system (Amersham Biosciences).

\section{HIF- $1 \alpha$ and VEGF- $A$ mRNA expression}

Total RNA was prepared from tissue samples using TRIzol reagent (Invitrogen) according to the manufacturer's instructions. RNA concentrations were determined spectrophotometically at $260 \mathrm{~nm}$ (DU 640 Spectrophotometer, Beckman Coulter, Sweden) and RNA quality was evaluated electrophoretically (presence of 28/18S RNA). Five hundred nanograms of RNA were reversed transcribed with Superscript II reverse transcriptase (Invitrogen). Real-time PCR was performed using the LightCycler SYBR Green I technology (Roche Diagnostics). Reactions were performed in a $20 \mu \mathrm{l}$ volume with $0.5 \mu \mathrm{M}$ primers and $3 \mathrm{mM}$ $\mathrm{MgCl}_{2}$. Nucleotides, Taq DNA polymerase, and buffer were included in the LightCycler-FastStart DNA Master SYBR Green I mix (Roche Diagnostics). Primers were designed by the nucleotide sequence relative to VEGF-A GeneBank accession no M32977 (5'-TGCCAAGTGGTCCCAGGCTGC-3', $5^{\prime}$-CTCATCTCTCCTATGTGCTGGCC- $3^{\prime}$ ) and HIF-1 $\alpha$ GeneBank accession no NM024359 (5'-CCAAGGAGCCTTAACC- $3^{\prime}$ and $5^{\prime}-$ CCGTGCCCCTACTATG- $3^{\prime}$ ). The PCR was initiated with a 10 -min enzyme activation step at $95^{\circ} \mathrm{C}$ followed by 45 cycles of $95^{\circ} \mathrm{C}$ denaturation for $15 \mathrm{~s}, 60^{\circ} \mathrm{C}$ annealing for $10 \mathrm{~s}$, and $72^{\circ} \mathrm{C}$ extension for $10 \mathrm{~s}$. To confirm amplification specificity, the PCR products were subjected to a melting curve analysis. Each experimental sample was run in duplicates and negative controls were always run in parallel. The quantification data were analyzed with the LightCycler analysis Software 3.5.3 (Roche Diagnostics). The relative values of the samples are calculated by a standard curve obtained by fivefold serial dilutions from a RNA sample in the intact group (double samples were run for each concentration). The same sample was used as calibrator for normalization between runs. The target values are presented as percent in comparison with the intact group.

\section{Statistical analysis}

Groups were compared using Mann-Whitney $U$ test with five to nine animals in each group. Values are given as mean \pm s.D., ${ }^{a} P$ value $<0.05$ was considered significant.

\section{Results}

Castration and testosterone treatment induce transient tissue hypoxia in the ventral and dorsolateral prostate (DLP) lobes

In all animals, marked hypoxyprobe staining of similar intensity was observed in parts of the renal tubules and in the renal medulla, and in central parts of liver lobuli confirming that all animals had received the marker and that it marked tissues know to be continuously hypoxic in normal rats (Fig. 1A, Arteel et al. 1995, Yin et al. 2002). Pimonidazole labeling does not detect minor or short-lived changes in hypoxia during a 1-h study period (Bennewith \& Durand 2004).

In the VP lobe in intact untreated rats some glands, i.e. those with a highly active secretory epithelium showed staining whereas closely adjacent atrophic glands were unstained (Fig. 1B) demonstrating that tissue oxygen levels are related not only to supply but also to consumption. The glands in the DLP lobe were uniformly unstained (Fig. 1C). Twenty-four hours after castration all glands in the VP lobe were intensively stained (Fig. 1D), whereas glands in the DLP lobe showed weak staining for hypoxia or remained unstained (Fig. 1E). Seven days after castration the glands in the VP (Fig. 1F) and DLP (Fig. 1G) lobes were lined with an atrophic epithelium that was generally unstained by the hypoxyprobe suggesting a normoxic balance now based on low flow and low metabolism (Lekås et al. 1997).

Castrated rats were treated with a single daily dose of testosterone and tissue hypoxia was studied at different times thereafter. Eight hours after testosterone treatment a slight increase in hypoxyprobe staining was observed whereas treatment for $24 \mathrm{~h}$ caused a major increase in staining intensity in the VP lobe (Fig. 1H). In castrated rats treated with daily injections of testosterone for 2,3 , or 4 days, the hypoxyprobe staining gradually decreased from very intense levels seen at day 1 to values similar to that in intact animals seen at 4 days (Fig. 1J). Glands in the DLP were stained at 1 (Fig. 1I) and 2 days after testosterone treatment and thereafter showed weak staining for hypoxia or were unstained (Fig. 1K, 4 days of testosterone treatment). Treatment of intact rats with the luteinizing hormone agonist hCG for $24 \mathrm{~h}$ resulted in a markedly increased hypoxyprobe staining in the epithelial cells in the VP, demonstrating that also stimulation of the prostate gland with endogenously increased testosterone levels result in local tissue hypoxia (data not shown).

To test whether the hypoxyprobe staining in prostate epithelial cells were caused by a non-hypoxic mechanism that could metabolize pimonidazole, prostate epithelial cells were grown in a normoxic or a hypoxic environment. Cells grown under normoxic conditions were not stained whereas cells grown under hypoxia were stained (Fig. 2), suggesting that hypoxyprobe staining of prostate epithelial cells is caused by hypoxia and not by unspecific uptake.

\section{Testosterone treatment increases HIF-1 $\alpha$ in the prostate}

Expression of a $116 \mathrm{kDa}$ protein referred to as HIF-1 $\alpha$ was detected in the VP and DLP lobes. Castration treatment caused slightly decreased levels of HIF- $1 \alpha$ protein in the VP lobe (Fig. 3A), but in the DLP HIF-1 $\alpha$ levels were increased 1 day after castration as described earlier (Fig. 3B, Shabsigh et al. 2001). Three days after castration HIF-1 $\alpha$ protein levels were decreased in both prostate lobes and 7 days after treatment HIF- $1 \alpha$ protein was almost absent, which is in line 

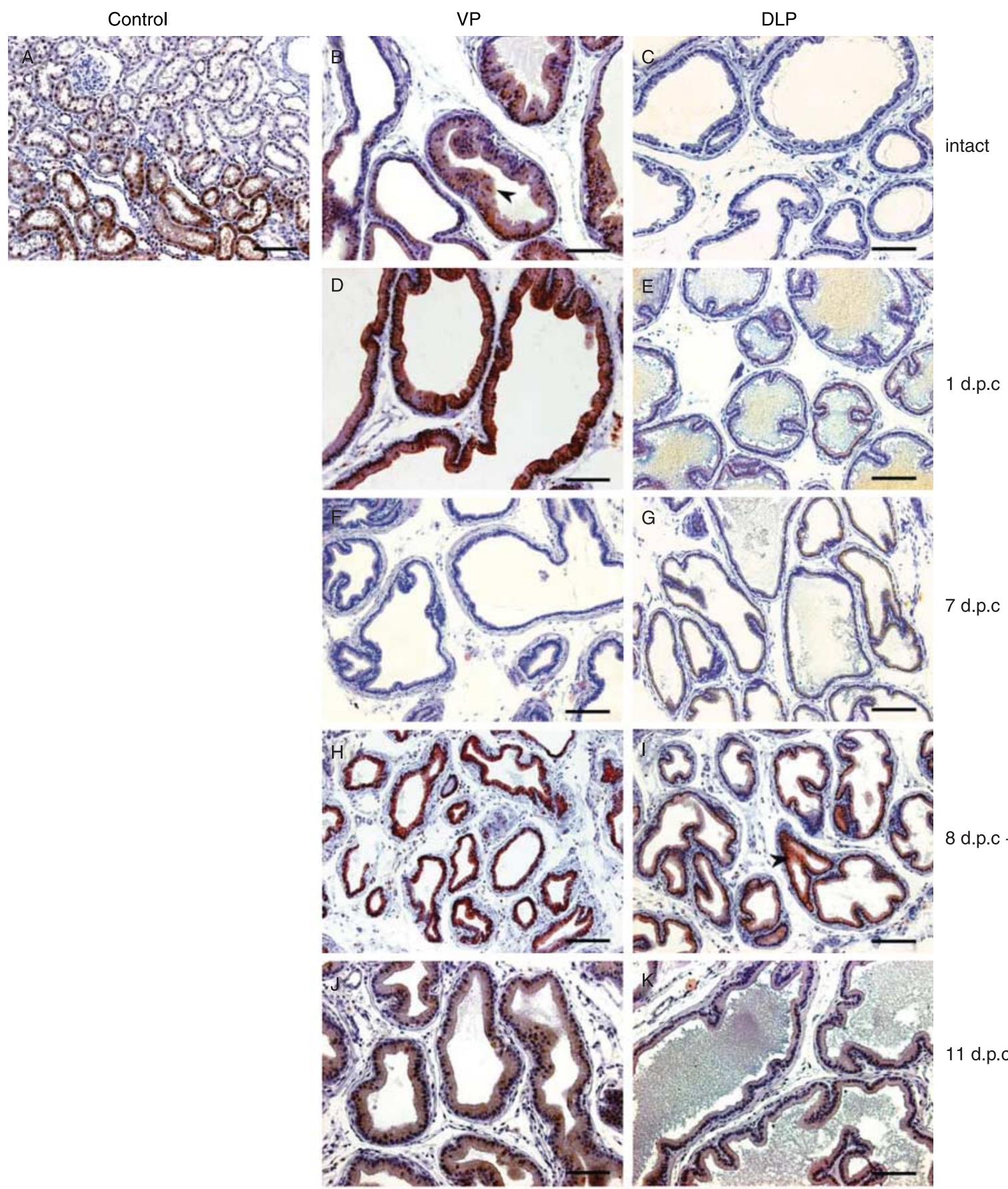

7 d.p.c
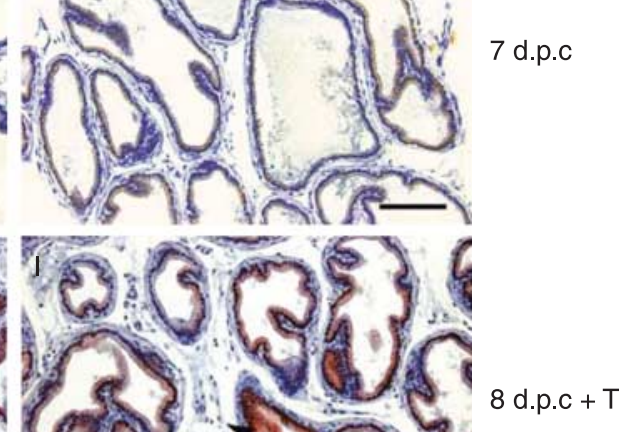

Figure 1 Section from the kidney $(A)$ and prostate glands $(B-K)$ in rats injected with the hypoxia marker pimonidazole hydrochloride and immunostained to visualize hypoxic cells, $200 \times$ magnifications. The scale bars are $100 \mu \mathrm{m}$. Hypoxic red-brown stained cells were observed in some renal tubules in intact rats (A). Some cylindrical luminal epithelial cells in the ventral prostate (VP) in intact rats were stained by the hypoxia marker (arrowhead, B) but adjacent atrophic glandular cells were unstained (B). Hypoxic cells were not observed in the dorsolateral prostate (DLP) in intact rats (C). One day post-castration (d.p.c.) all glandular epithelial cells in the VP were stained by the hypoxia marker (D) and the DLP showed weak staining for hypoxia (E). Seven days post-castration the atrophic epithelial cells in the ventral prostate were unstained by the hypoxia marker (F) and the DLP showed weak staining (G). One day after testosterone treatment (and 8 days after castration, d.p.c. + T) all glandular epithelial cells in the VP were stained by the hypoxia marker $(\mathrm{H})$. In the DLP, some hypoxic glands (arrowheads) were observed 1 day after testosterone treatment in castrated rats (I). After 4 days of testosterone treatment (and 11 days after castration), the glandular epithelial cells in the VP and DLP were only weakly stained by the hypoxia marker (J and K). 

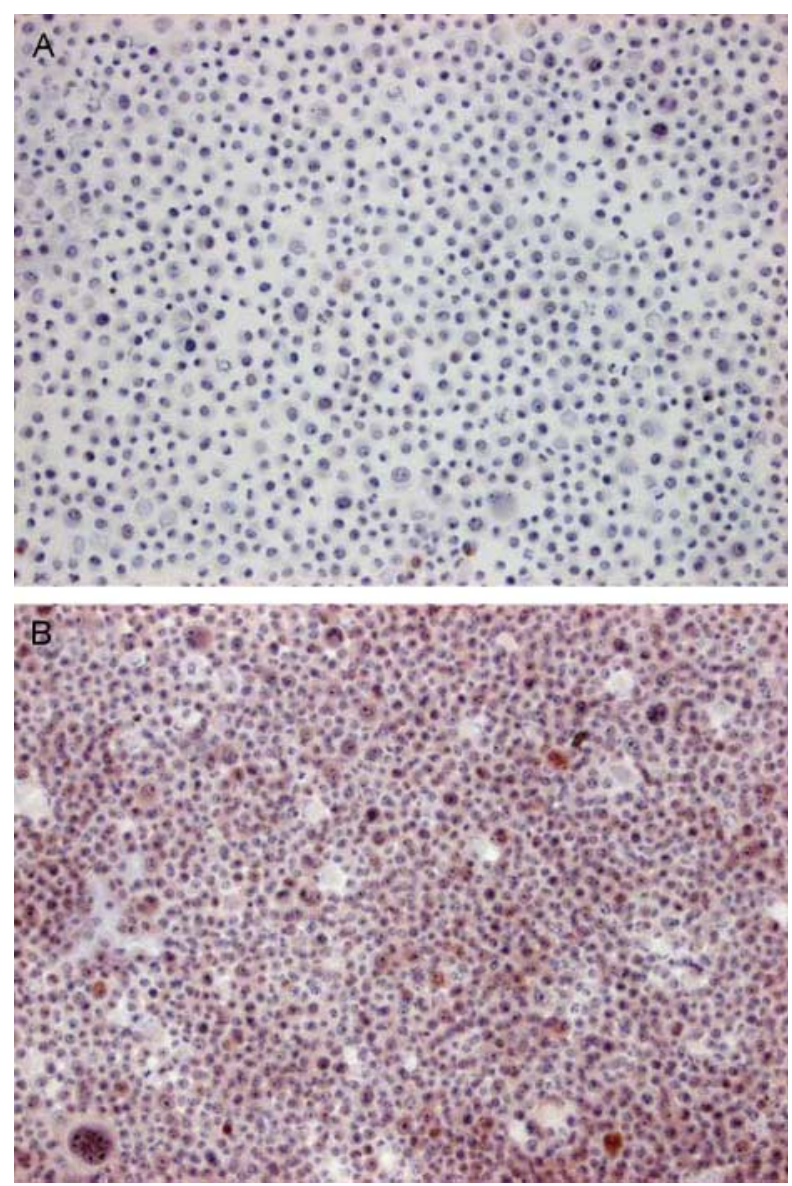

Figure 2 Prostate epithelial cells (RWPE-1) were incubated with pimonidazole hydrochloride and immunostained to visualize hypoxic cells $(200 \times$ magnifications). Cells grown in normoxia $\left(21 \% \mathrm{O}_{2}\right)$ did not stain $(\mathrm{A})$ whereas cells grown in hypoxia $\left(1 \% \mathrm{O}_{2}\right.$, B) were intensely stained.

with the lack of hypoxyprobe staining at this time point (Fig. 3). Testosterone treatment of castrated animals resulted, within 2 days, in increased HIF- $1 \alpha$ mRNA (Table 1) and protein levels in the VP and DLP (Fig. 3).

\section{Testosterone treatment affects HIF target gene expression}

Two HIF target genes, VEGF-A and carbonic anhydrase 9 (CA-9), were detected in the rat VP and DLP (Fig. 3). VEGF-A mRNA expression in the VP was unaffected at one and three days, but decreased 7 days after castration (Table 1). The protein levels of VEGF-A in the VP were decreased at two days and undetectable 7 days after castration (Fig. 3A). In line with the hypoxyprobe data, castration did not affect VEGF mRNA and protein levels as drastically in the DLP as in the VP (Fig. 3B). Testosterone treatment, however, increased VEGFA expression in both the VP and DLP in castrated rats (Table 1, Fig. 3). In line with VEGF castration decreased CA-9 protein expression 7 days after treatment in the VP but CA-9 protein levels in the DLP were only slightly affected by castration (Fig. 3). CA-9 protein was increased in both the VP and DLP after testosterone treatment.

\section{Androgens induce expression of HIF- $1 \alpha$ in prostate epithelial cells via $E G F-R$}

Treatment with R1881, a non-metabolizable synthetic androgen, showed an increase in HIF-1 $\alpha$ expression after 2 days in RWPE-1 cells (Fig. 4). This induction was inhibited by the AR inhibitor flutamide demonstrating that androgens act through AR. Androgens have been shown to increase HIF-1 $\alpha$ in prostate cancer cells indirectly via EGFR (Mabjeesh et al. 2003). We therefore tested if androgens regulate HIF- $1 \alpha$ expression in nonmalignant prostate epithelial cells in a similar way. Gefitinib (Iressa) an EGFR tyrosine kinase inhibitor decreased the induction of HIF-1 $\alpha$ in response to either EGF or R1881 stimulation in RWPE-1 cells (Fig. 4). To verify that gefitinib had the same effect also in vivo, 7 days castrated animals were treated with gefitinib or vehicle during testosterone stimulation. In this situation, gefitinib treatment had no effect on HIF- $1 \alpha$ protein expression, but led to a decrease in VEGF protein levels (Fig. 5) and prostate tissue growth (Hammarsten et al. 2007). Together these results indicate that androgens can induce HIF- $1 \alpha$ expression in prostate cells at least by two ways, either by a major stimulation of metabolism resulting in hypoxia or indirectly via the EGF receptor tyrosine kinase/ $\mathrm{PI} 3 \mathrm{~K} / \mathrm{Akt}$ signaling pathway.

\section{Discussion}

In the present study, we examined effects of castration and testosterone treatment on local tissue oxygen levels in the rat prostate using a morphological marker of tissue hypoxia (marks tissues with $\mathrm{pO}_{2}$ level below $10 \mathrm{mmHg}$ ) and correlated this to changes in HIF- $1 \alpha$ and HIF target gene expression. The novel finding was that testosterone stimulation caused transient prostate epithelial cell hypoxia and that this may stimulate angiogenesis and coordinate vascular and glandular growth. Transient hypoxia could thus be of importance during prostate involution following androgen withdrawal (see introduction) and during testosterone-stimulated prostate growth.

The VP is known to be the most androgen-dependent part of the prostate gland in rodents, and this lobe is generally used in studies aiming to elucidate how testosterone influence prostate metabolism, cell proliferation, and cell death (Kurita et al. 2001). Castration reduces metabolism and consequently oxygen consumption in the prostate (Lee 1981), but also prostate blood flow (Lekås et al. 1997). Tissue hypoxia was observed 1-3 days after castration (Shabsigh et al. 2001), and not at 7 days (this study). Together, these observations suggest that castration only transiently disturbs the balance between local oxygen demand and supply. Early after castration, flow and oxygen supply apparently decreased more than metabolism resulting in transient tissue hypoxia. New normoxic equilibrium, with low metabolism and low flow, was in fact reached at 7 days after 
A

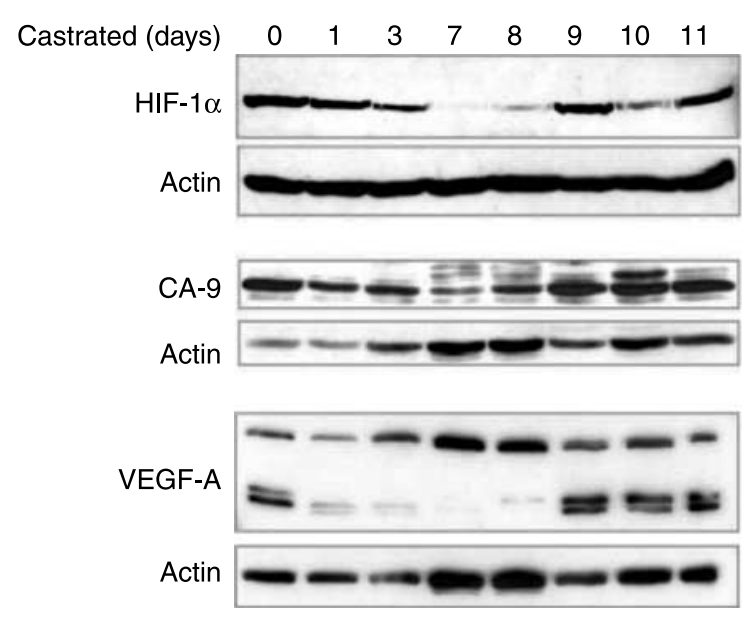

B $\underline{\text { Testosterone treated }}$
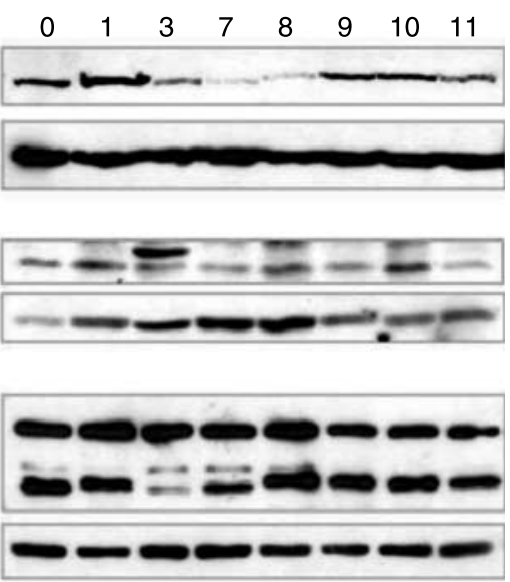

Figure 3 Expression of HIF-1 $\alpha$, VEGF-A, and CA-9 protein in the rat ventral (A) and dorsolateral (B) prostate after castration and following castration + testosterone stimulation for 1 day, 2, 3, and 4 days (as indicated). Each group was a pool of three to five rats in the Western blot procedure. Actin was used as a control for equal loading.

castration. In line with this, total VP protein synthesis is only slightly affected (Lee 1981), whereas flow is markedly reduced $24 \mathrm{~h}$ after castration (Lekås et al. 1997). At 7 days, both flow and metabolism are markedly reduced (Lee 1981, Lekås et al. 1997). The suggestion that tissue oxygen levels in the prostate are related both to oxygen supply and demand was also supported by the observation that localized tissue hypoxia could be seen in highly active secretory glands in the normal VP but not in closely adjacent glands lined with a more inactive atrophic epithelium glands all probably supported by the same vasculature.

In other tissues, local hypoxia is a major stimulator of VEGF (Dor et al. 2001, Giordano \& Johnson 2001), but in the prostate the hypoxia response is inhibited in the absence of androgens (Stewart et al. 2001). This may explain why VEGF expression was not increased in the VP early after castration. This may also be true for expression of other HIF target genes like CA-9 in the prostate androgen free environment. Furthermore, ischemia may play a slightly different role in different parts of the prostate; the DLP is less androgen sensitive than the VP (Banerjee et al. 1995). Glandular weight in the DLP is reduced after castration, but this is neither accompanied by a major apoptotic cell death in the epithelium (Banerjee et al. 1995, Kurita et al. 2001) nor by changes in blood flow (Lekås et al. 1997). In line with this, transient castration-induced tissue hypoxia and changes in the expression of HIF target genes in this study were not in the same magnitude in the DLP as in the VP.

Testosterone-stimulated growth of the VP and DLP in castrated rats is accompanied by vasodilatation, increased blood flow, endothelial cell proliferation and vascular growth, and increased epithelial cell VEGF synthesis (Joseph et al. 1997, Lekås et al. 1997, Franck Lissbrant et al. 1998, Häggström et al. 1999, Lissbrant et al. 2001). The testosterone-stimulated increase in endothelial cell proliferation and vascular growth and subsequent organ growth can

Table 1 Relative differences of hypoxia-inducible factor- $1 \alpha$ (HIF-1 $\alpha)$ and vascular endothelial growth factor-A (VEGF-A) mRNA in the rat ventral and dorsolateral prostate lobes at different times after castration and at different times after testosterone treatment $(n=5-9$ rats), for details see text

\begin{tabular}{|c|c|c|c|c|}
\hline & \multicolumn{2}{|l|}{ Ventral prostate } & \multicolumn{2}{|c|}{ Dorsolateral prostate } \\
\hline & HIF-1 $\alpha(\% \pm$ s.D. $)$ & VEGF-A (\%土s.D.) & HIF-1 $\alpha(\% \pm$ s.D. $)$ & 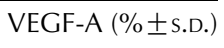 \\
\hline Intact & $100 \pm 44$ & $100 \cdot 0 \pm 17$ & $100 \pm 72$ & $100 \cdot 0 \pm 19$ \\
\hline 1 day castrated & $116 \pm 51$ & $98 \cdot 4 \pm 11$ & $123 \pm 69$ & $106 \cdot 2 \pm 30$ \\
\hline 3 days castrated & $146 \pm 48$ & $100 \cdot 3 \pm 10$ & $172 \pm 117$ & $\mathrm{NA}$ \\
\hline 7 days castrated & $104 \pm 48$ & $35 \cdot 0 \pm 28 *$ & $98 \pm 56$ & $79 \cdot 2 \pm 44$ \\
\hline Castrated + testosterone 1 day & $84 \pm 21$ & $63 \cdot 0 \pm 32^{+}$ & $174 \pm 152$ & $160 \cdot 2 \pm 40^{*,+}$ \\
\hline Castrated + testosterone 2 days & $160 \pm 44^{+}$ & $102 \cdot 8 \pm 0 \cdot 6^{+}$ & $114 \pm 50$ & $89 \cdot 5 \pm 10$ \\
\hline Castrated + testosterone 3 days & $180 \pm 77$ & $105 \cdot 9 \pm 13^{+}$ & $99 \pm 48$ & NA \\
\hline
\end{tabular}

S.D., standard deviation; NA, not analyzed. *Significantly different than in intact rats, $P<0 \cdot 05$, Mann-Whitney $U$ test. ${ }^{\dagger}$ Significantly different than in 7 -day castrated rats, $P<0 \cdot 05$, Mann-Whitney $U$ test. 


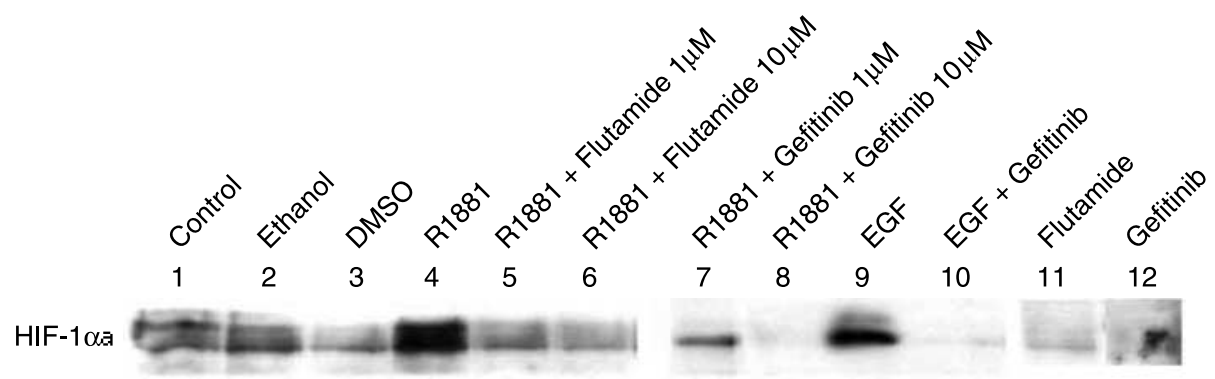

Figure 4 R1881 (synthetic androgen) induces HIF-1 $\alpha$ protein in RWPE-1 cells. The androgen receptor inhibitor, flutamide, and EGF-R inhibitor, gefitinib, blocks HIF-1 $\alpha$ expression in response to R1881 or EGF. RWPE- 1 cells were cultured in androgen-free medium for $24 \mathrm{~h}$ and then treated with vehicle, R1881, R1881 + flutamide, R1881 + gefitinib, EGF, EGF + gefitinib, flutamide, and gefitinib for $48 \mathrm{~h}$. The experiment was repeated thrice with no apparent changes.

be inhibited by blocking VEGF (Lissbrant et al. 2004), demonstrating that testosterone-stimulated VP growth is angiogenesis dependent and that VEGF is a central mediator of this effect. Direct effects of androgens on prostate blood vessels are, however, also possible as mural cells in prostate blood vessels express AR (Johansson et al. 2005). In the present study, we demonstrate that testosterone treatment transiently induces tissue hypoxia in the VP and DLP, and suggest that this is caused by a temporary mismatch between a rapid major increase in metabolism and oxygen demands (Sensibar et al. 1990) and an apparently insufficient moderate increase in blood flow (Lekås et al. 1997). We also suggest that transient tissue hypoxia, by increasing local HIF- $1 \alpha$ and VEGF secretion and consequently vascular growth is an important component in androgen-stimulated prostate growth. Later during continuous testosterone stimulation when local oxygen demands and supply are balanced the tissue will again become normoxic, VEGF will normalize, and additional tissue growth will not take place (Sordello $e t$ al. 1998). Our hypothesis that testosterone-induced vascular and subsequent tissue growth in the prostate could be driven and coordinated by a temporary mismatch between local oxygen consumption and delivery is in line with the recent opinion that tissue growth and regression in general could be regulated by local tissue oxygen (Dor et al. 2001, Giordano \& Johnson 2001, Lee et al. 2001). Embryonic development, tumor, and tissue growth require angiogenesis to provide blood flow to an increasing cellular mass. How the growing tissue senses the need for increased blood supply and how it signals this to the vasculature is beginning to be explored. Tissue oxygen is at the centre of a feedback between the vasculature and the tissue it serves (Dor et al. 2001). Tissue growth and/or increased metabolic activity cause increased local oxygen consumption. This leads to a moderate sub-pathological decrease in tissue oxygen, so-called local 'physiological hypoxia' (Dor et al. 2001). Hypoxia, by increasing HIF-1 $\alpha$, directly stimulates secretion of angiogenic factors, principally VEGF-A (Semensa 2003). Interestingly, hypoxia may augment testosterone-stimulated prostate growth also by increasing the sensitivity of the AR to androgen stimulation
(Park et al. 2006). If local tissue hypoxia drives prostate growth in synergy with androgens this may explain previous observations of links between atherosclerosis, prostate hypoxia, and the pathogenesis of benign prostate hyperplasia and cancer. Atherosclerosis in the arteries supplying the prostate has been associated with an increase in the risk of benign prostate hyperplasia (Harvey 1995, Ghafar et al. 2002, Berger et al. 2006) and prostate cancer (Hager et al. 2006), and prostate cancer is associated with tissue hypoxia (Movsas et al. 2001) and increased HIF-1 $\alpha$ levels (Kimbro \& Simons 2006).

Prostate epithelial cell HIF-1 $\alpha$ expression is, apart from hypoxia, also stimulated by testosterone in vitro under normoxic conditions. This increase is blocked by flutamide showing that HIF pathway is a direct downstream target of androgen action. In addition, prostate epithelial cell VEGF secretion is stimulated by testosterone in vitro (Sordello et al. 1998), and HIF-1 regulates androgen-induced VEGF expression in prostate cancer cells (Mabjeesh et al. 2003). Several studies indicate that the effect of

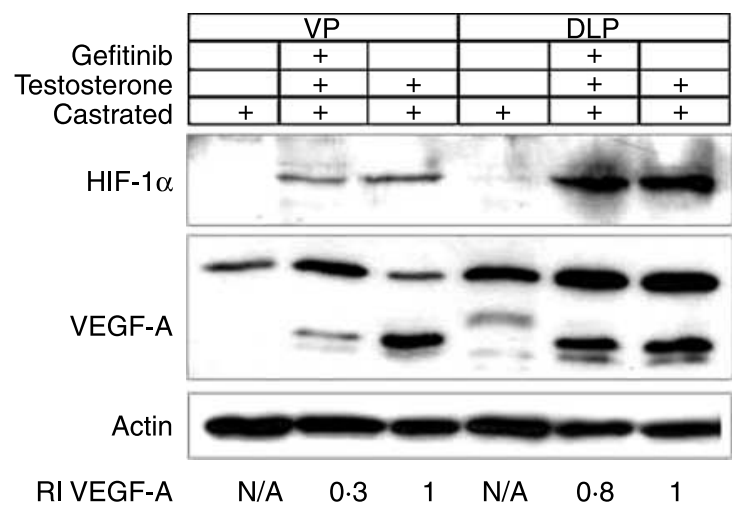

Figure 5 Gefitinib treatment in 7 day castrated rats during testosterone stimulation had no affects on HIF- $1 \alpha$ protein expression in neither the ventral prostate (VP) nor the dorsolateral prostate (DLP). VEGF-A protein was down-regulated by gefitinib treatment during testosterone stimulation in the VP and to a lesser degree in the DLP compared with vehicle-treated + testosteronestimulated rats. Each group includes three rats in the Western blot procedure. The relative index (RI) for VEGF-A was normalized against actin relative intensity. 
androgen on HIF- $1 \alpha$ activity in prostate cancer cells in vitro is indirect and regulated via increased activity in the EGF receptor tyrosine kinase/PI3K/Akt signaling pathway (Zhong et al. 2000, Laughner et al. 2001, Mabjeesh et al. 2003). Moreover, EGF enhances the expression of VEGF in androgen-independent prostate cancer cells (Ravindranath et al. 2001). This study demonstrated that EGF treatment increased levels of HIF-1 $\alpha$ in non-malignant prostate epithelial cells and this was inhibited by gefitinib (Iressa). In line with earlier studies, gefitinib also inhibited androgen-stimulated normoxic expression of HIF-1 $\alpha$ in prostate epithelial cells in vitro. Together, this indicates that androgens act through the EGF receptor tyrosine kinase/PI3K/ Akt signaling pathway. However, gefitinib did not prevent the testosterone-stimulated increase in HIF- $1 \alpha$ expression in castrated animals suggesting that the hypoxia induced increase in HIF- $1 \alpha$ is not dependent on increased EGFR signaling in vivo. In an earlier study by our group, this gefitinib treatment suppressed testosterone-stimulated EGFR phosphorylation and tissue growth in vivo (Hammarsten et al. 2007). Gefitinib+ testosterone treatment in vivo did, however, reduce VEGF. This can possibly be explained by a direct effect on VEGF transcription via EGFR and phosphorylation of Sp-1 (Pore et al. 2006).

\section{Conclusions}

Testosterone-stimulated prostate growth in castrated rats is accompanied by transient hypoxia in prostate epithelial cells. This hypoxia may drive and coordinate vascular and tissue growth in the prostate by increasing the sensitivity to androgens (Park et al. 2006), and by increasing HIF-1 $\alpha$ and VEGF synthesis. In addition, testosterone may use an EGFRdependent mechanism to increase HIF-1 $\alpha$ and VEGF synthesis also under normoxic situations.

\section{Acknowledgements}

Skilful technical assistance was given by Ms Sigrid Kilter, Ms Ulla-Stina Spetz, Ms Birgitta Ekblom, Ms Elisabeth Dahlberg, and Ms Pernilla Andersson. This study was supported by grants from the Swedish Cancer Foundation, the Swedish Research Council, the Lion's Cancer Research Foundation, Umeå University, Åke Wibergs Foundation, Sweden, and the University Hospital in Umea. The authors declare that there is no conflict of interest that would prejudice the impartiality of this work.

\section{References}

Arteel GE, Thurman RG, Yates JM \& Raleigh JA 1995 Evidence that hypoxia markers detect oxygen gradients in liver: pimonidazole and retrograde perfusion of rat liver. British Journal of Cancer 72 889-895.

Banerjee PP, Banerjee S, Tilly KI, Tilly JL, Brown TR \& Zirkin BR 1995 Lobe-specific apoptotic cell death in rat prostate after androgen ablation by castration. Endocrinology 136 4368-4376.
Bennewith KL \& Durand RE 2004 Quantifying transient hypoxia in human tumor xenografts by flow cytometry. Cancer Research 64 6183-6189.

Berger AP, Horninger W, Bektic J, Pelzer A, Spranger R, Bartsch G \& Frauscher F 2006 Vascular resistance in the prostate evaluated by colour Doppler ultrasonography: is benign prostatic hyperplasia a vascular disease? BJU International 98 587-590.

Buttyan R, Ghafar MA \& Shabsigh A 2000 The effects of androgen deprivation on the prostate gland: cell death mediated by vascular regression. Current Opinion in Urology 10 415-420.

Chou S-C, Flood PM \& Raleigh JA 1996 Marking hypoxic cells for complement and cytotoxic T lymphocyte-mediated lysis: using pimonidazole. British Journal of Cancer 74 213-216.

Dor Y, Proat R \& Keshet E 2001 Vascular endothelial growth factor and vascular adjustments to perturbations in oxygen homeostasis. American Journal of Physiology and Cell Physiology 280 C1367-C1374.

Folkman J 1998 Is tissue mass regulated by vascular endothelial cells? Prostate as the first evidence Endocrinology 139 441-442.

Franck Lissbrant I, Häggström S, Damber JE \& Bergh A 1998 Testosterone stimulates angiogenesis and vascular regrowth in the ventral prostate in castrated adult rats. Endocrinology 139 451-456.

Ghafar MA, Puchner PJ, Anastasiadis AG, Cabelin MA \& Buttyan R 2002 Does the prostatic vascular system contribute to the development of benign prostatic hyperplasia? Current Urology Reports 3 292-296.

Giordano FJ \& Johnson RS 2001 Angiogenesis: the role of the microenvironment in flipping the switch. Current Opinion in Genetics and Development 11 35-40.

Hager M, Mikuz G, Bartsch G, Kolbitsch C \& Moser PL 2006 The association between local atherosclerosis and prostate cancer. British Journal of Urology 99 46-48.

Häggström S, Franck Lissbrant I, Bergh A \& Damber JE 1999 Testosterone induces vascular endothelial growth factor synthesis in the ventral prostate in castrated rats. Journal of Urology 161 1620-1625.

Häggström S, Stattin P, Wikström P, Bergh A \& Damber JE 2001 Castrationinduced reduction of vascular endothelial growth factor expression in benign human prostate tissue is lost in advanced prostate cancer. BJU International 88 110-116.

Hammarsten P, Rudolfsson SH, Henriksson R, Wikstrom P \& Bergh A 2007 Inhibition of the epidermal growth factor receptor enhances castrationinduced prostate involution and reduces testosterone-stimulated prostate growth in adult rats. Prostate $67573-581$.

Harvey H 1995 A unifying hypthesis that links benign prostate hyperplasia and prostatic intraepithelial neoplasia with prostate cancer. Pathology, Research and Practice 191 924-934.

Isaacs JT, Furuya Y \& Berges R 1994 The role of androgen in the regulation of programmed cell death/apoptosis in normal and malignant prostate tissue. Seminars in Cancer Biology 5 391-400.

Johansson A, Rudolfsson SH, Wikstrom P \& Bergh A 2005 Altered levels of angiopoietin 1 and tie 2 are associated with androgen-regulated vascular regression and growth in the ventral prostate in adult mice and rats. Endocrinology 146 3463-3470.

Joseph IB, Nelson JB, Denmeade SR \& Isaacs JT 1997 Androgens regulate vascular endothelial growth factor content in normal and malignant prostatic tissue. Clinical Cancer Research 3 2507-2511.

Kimbro KS \& Simons JW 2006 Hypoxia-inducible factor-1 in human breast and prostate cancer. Endocrine-Related Cancer 13 739-749.

Kurita T, Wang YZ, Donjacour AA, Zhao C, Lydon JP, O'Malley BW, Isaacs JT, Dahiya R \& Cunha GR 2001 Paracrine regulation of apoptosis by steroid hormones in the male and female reproductive organs. Cell Death and Differentiation 8 192-200.

Laughner E, Taghavi P, Chiles K, Mahon PC \& Semenza GL 2001 HER2 (neu) signaling increases the rate of hypoxia-inducible factor 1alpha (HIF-1alpha) synthesis: novel mechanism for HIF-1-mediated vascular endothelial growth factor expression. Molecular and Cellular Biology 21 3995-4004.

Lee C 1981 Physiology of castration-induced regression in rat prostate. In The Prostatic Cell: Structure and Function Part A. New York: AR Liss.

Lee YM, Jeong C-H, Koo S-Y, Son JM, Song HS, Bae S-K, Raleigh JA, Chung H-Y, Yoo M-A \& Kim K-W 2001 Determination of hypoxic regions by hypoxia marker in developing mouse embryos in vivo: a possible signal for vessel development. Developmental Dynamics 220 175-186. 
Lekås E, Johansson M, Widmark A, Bergh A \& Damber JE 1997 Decrement of blood flow precedes the involution of the ventral prostate in the rat after castration. Urological Research 25 309-314.

Lekås E, Engstrand C, Bergh A \& Damber JE 1999 Transient ischemia induces apoptosis in the ventral prostate of the rat. Urological Research 27 174-179.

Lissbrant IF, Lissbrant E, Damber JE \& Bergh A 2001 Blood vessels are regulators of growth, diagnostic markers and therapeutic targets in prostate cancer. Scandinavian Journal of Urology and Nephrology 35 437-452.

Lissbrant IF, Hammarsten P, Lissbrant E, Ferrara N, Rudolfsson SH \& Bergh A 2004 Neutralizing VEGF bioactivity with a soluble chimeric VEGF receptor protein $\mathrm{flt}(1-3) \operatorname{IgG}$ inhibits testosterone stimulated prostate growth in castrated mice. Prostate 58 57-65.

Mabjeesh NJ, Willard MT, Frederickson CE, Zong H \& Simons J 2003 Androgens stimulate hypoxia-inducible factor 1 activation via autocrine loop of tyrosine kinase receptor/phosphatidylinositol $3^{\prime}$-kinase/protein kinase B in prostate cancer cells. Clinical Cancer Research 9 2416-2425.

Movsas B, Chapman JD, Hanlon AL, Horwitz EM, Pinover WH, Greenberg RE, Stobbe C \& Hanks GE 2001 Hypoxia in human prostate carcinoma. American Journal of Clinical Oncology 24 458-461.

Park SY, Kim YJ, Gao AC, Mohler JL, Onate SA, Hidalgo AA, Ip C, Park EM, Yoon SY \& Park YM 2006 Hypoxia increases androgen receptor activity in prostate cancer cells. Cancer Research 15 5121-5129.

Pore N, Jiang Z, Gupta A, Cerniglia G, Kao GD \& Maity A 2006 EGFR tyrosine kinase inhibitors decrease VEGF expression by both hypoxiainducible factor (HIF)-1-independent and HIF-1-dependent mechanisms. Cancer Research 66 3197-3204.

Raleigh JA, Chou SC, Bono EL, Thrall DE \& Varia MA 2001 Semiquantitative immunohistochemical analysis for hypoxia in human tumors. International Journal of Radiation Oncology, Biology, Physics 49 $569-574$

Ravindranath N, Wion D, Brachet P \& Djakiew D 2001 Epidermal growth factor modulates the expression of vascular endothelial growth factor in the human prostate. Journal of Andrology 22 432-443.

Semensa GL 2003 Targeting HIF-1 for cancer therapy. Nature Reviews. Cancer $3721-732$.
Sensibar JA, Alger B, Tseng A, Berg L \& Lee C 1990 Proteins of the rat prostate. III. Effect of testosterone on protein synthesis by the ventral prostate of castrated rats. Journal of Urology 143 161-166.

Shabisgh A, Tanji N, D'Agati V, Burchardt M, Rubin M, GoluboffET, Heitjan D, Kiss A \& Buttyan R 1999 Early effects of castration on the vascular system of the rat ventral prostate gland. Endocrinology 140 1920-1926.

Shabsigh A, Ghafar MA, de la Taille A, Burchardt M, Kaplan SA, Anastasiadis AG \& Buttyan R 2001 Biomarker analysis demonstrates a hypoxic environment in the castrated rat ventral prostate gland. Journal of Cellular Biochemistry $\mathbf{8 1}$ 437-444.

Sordello S, Bertrand N \& Plouet J 1998 Vascular endothelial growth factor is up-regulated in vitro and in vivo by androgens. Biochemical and Biophysical Research Communications 251 287-290.

Stewart RJ, Panigrahy D, Flynn E \& Folkman J 2001 Vascular endothelial growth factor expression and tumor angiogenesis are regulated by androgens in hormone responsive human prostate carcinoma: evidence for androgen dependent destabilization of vascular endothelial growth factor transcripts. Journal of Urology 165 688-693.

Yin M, Zhong Z, Connor HD, Bunzendahl H, Finn WF, Rusy I, Li X, Raleigh JA, Mason RP \& Thurman RG 2002 Protective effect of glycine on renal injury induced by ischemia-reperfusion in vivo. American Journal of Physiology 282 F417-F423.

Zhong H, Chiles K, Feldser D, Laughner E, Hanrahan C, Georgescu MM, Simons JW \& Semenza GL 2000 Modulation of hypoxia-inducible factor 1alpha expression by the epidermal growth factor/phosphatidylinositol 3-kinase/PTEN/AKT/FRAP pathway in human prostate cancer cells: implications for tumor angiogenesis and therapeutics. Cancer Research $\mathbf{1 5}$ $1541-1545$.

Received in final form 16 October 2007

Accepted 23 October 2007

Made available online as an Accepted Preprint 23 October 2007 